\title{
A MEDICINA, \\ A PSICANÁLISE E A PSICOSSOMÁTICA. \\ O USUFRUTO DO CORPO
}

\author{
Milton Lopes de Souza
}

A

psicanálise, cada vez mais, neste final de século, vem possibilitando um diálogo com outras áreas do conhecimento, sobretudo com a medicina, da qual se origina, com a pedagogia, o direito, a filosofia e com o discurso universitário. A partir destes "casamentos", novas perspectivas, reformulações de conceitos com consequências clínicas têm surgido.

No que tange às relaçòes da psicanálise com a medicina, a psicossomática psicanalítica surge como uma possibilidade de perceber o sofrimento vivido pelo homem no seu psicossoma, unidade não cartesiana do ser vivente.

A psicossomática vem se desenvolvendo numa espécie de interface, um espaço de discussão entre o discurso da medicina e o discurso do psíqui$\mathrm{co}$, abrangendo pesquisas na imunolo- gia, na endocrinologia e na neurociência, com a descoberta de peptídeos e neurotransmissores em número crescente, que seduzem ao encontro da tào esperada "passagem" do psíquico para o somático.

No campo da psicanálise, Freud (1974a, 1974b, 1974c) chegou a considerar a participação do inconsciente como um determinante não somente nas ações psíquicas mas também nas somáticas, sobretudo em artigos destinados à neurose histérica, neurastenia e neuroses atuais mas preferiu não se aprofundar na questão da psicossomática.

Foi a partir de G.Groddeck (1984), considerado o pai da psicossomática, que o corpo volta a ter o seu lugar como o palco do teatro da vida, onde as cenas fantasmáticas se atualizam em tragédias. Digo que é um retorno, por-

Prof. Assist. Dr. do Depto. de Clínica Médica da Universidade Estadual de Campinas; pesquisador do Laboratório de Psicopatologia Fundamental do Núcleo de Psicanálise do Programa de Estudos Pós-Graduados em Psicologia Clínica da Pontifícia Universidade Católica da São Paulo; membro da Sociedade Campinense de Psicanálise e da Associação Brasileira de Medicina Psicossomática. 
que para a medicina da antigüidade o ser humano era tomado como uma unidade vivente, e a sede da alma nào estava no cérebro.

Tanto Freud, como Groddeck eram clínicos, Freud, um clínico da alma, Groddeck, um clínico geral, das doenças crônicas, dos banhos, das massagens e da psicanálise. Acredito que é da clínica que nascem as teorias e jamais o contrário.

Isto posto, pretendo nesta oportunidade considerar a psicossomática do ponto de vista da psicanálise e da psicopatologia, enfocando a questão do Gozo (Genuss, jouissance, enjoyment) e da Castração, desenvolvidos sobretudo em Freud e Lacan.

Onde fica a sede da alma humana? Quando o Homem ama, tem medo, se apaixona, se admira diante de uma obra de arte, se sente atraído pela visão do belo sexo, leva um susto, se vê diante da morte de alguém querido ou de sua própria; quando sonha, acorda subitamente de um pesadelo... onde registra e o que faz com todos os estímulos que recebe e produz?

Basta ater-nos a lembranças como estas, para percebermos que é o corpo quem primeiro registra e primeiro reage aos estímulos, sejam exteriores ou interiores. O medo, nos atinge diretamente no epigastro, o ódio, no fígado e na vesícula biliar; o amor, no coração e nas cordas vocais; a atração sexual, nos órgãos genitais....Talvez por isto, na antigüidade, Hipócrates teria formulado a teoria dos humores, onde o melancólico por exemplo, sofreria pela bile negra em excesso, intoxicando o seu corpo.

É somente num segundo momento, que o pensamento intervém, numa tentativa de reconhecer, pela elaboração simbólica da linguagem, este fragmento de real ameaçador ou inquietante. Portanto, o sujeito humano, em função de sua inserção na cultura, dispòe de uma maquinaria ou de uma "linguisteria", no dizer de Nestor Braunstein (1992), para reconhecer e barrar a invasão do estranho sobre seu corpo.

Isto nos leva a pensar sobre o ponto de partida. O filhote homo sapiens, não é ainda humano ao nascer, sua bagagem genética não the assegura a sapiência e sua humanização depende do um outro que vai acolher o seu grito (Nebenmensch). Nesta fase de extrema fragilidade e desamparo (Hilflosigkeit), a criança nada mais é que um " $x$ " diante do desejo do Outro da linguagem, ela é apenas sensaçòes sem nenhum nome: luz, peso, frio, molhado, cocô, xixi, fome, sede, dor; estes, ela só vai associá-los porque alguém irá lhe ensinar. E qual não é o júbilo que constatamos na criança que passa a articular as primeiras palavras para poder traduzir o que sente!

Quem teve filhos pequenos ou vive a clínica pediátrica, sabe o quanto a criança utiliza o corpo para se comunicar diante de situações de angústia, de medo ou de euforia mesmo, como as famosas febres emocionais, diarréias, constipações, crises asmáticas e tantas outras, e constata a dissoluçào destes sintomas a partir do 
momento em que consiga verbalizá-las ou exprimi-las em desenhos ou brincadeiras.

Vale a pena, neste momento lembrar a Carta 52 de Freud (cf. Kaufmann, 1996) e o esquema que ele propòe para a estruturação do aparelho psíquico:

tre). É justamente esta falta, este fragmento de real que se perde, objeto a de Lacan, que nos institui como seres desejantes, que movimenta a pulsão em demandas que nada mais fazem que reafirmar esta falta.

A primeira conceitualização de gozo em Freud, vamos encontrá-la em "Os chistes e sua relaçào com o inconsciente", de 1905 (1974c), quando examina a transmissão do rasgo de espírito entre a primeira e a terceira pessoa. Ele afirma que "... a comunicação a uma outra pessoa proporciona o gozo", e,

Deste esquema, que já associa elementos da primeira e segunda tópica, apenas nos serviremos para retirar a noção de gozo (Genuss), que é diferente da idéia de prazer, podendo até serem opostos.

$O$ homem não tem acesso às experiências diretamente obtidas do real (Wabrnehmung), às cenas primárias onde se viu tramado na história que o precedeu ou ao lugar que veio ocupar no desejo de sua màe. O trabalho do inconsciente já supòe uma cifragem anterior desta percepção. As produções do inconsciente, sejam os sonhos, os atos falhos, os chistes, as atuaçôes (acting out), estão já numa relação de deslocamento e condensação (em Lacan diríamos metáfórica e metonímica) com esta Coisa (das Ding) inacessível, para sempre perdida, em decorrência da inserção do homem na linguagem.

No entanto, como Freud propõe, em Mais além do princípio do prazer, é a pulsão de morte que é fundamental à existência, pois buscamos sempre uma tentativa de retorno a este elo perdido, a este fragmento de real que se perde em cada tentativa de dizer a Coisa. Lacan, a partir da leitura de Freud, postula que o homem é um ser de falta, "falta para ser" e um "falasser", (Parlê- mais abaixo, que pelo efeito desencadeado sobre um novo: "...recupera-se um fragmento de possibilidade de gozo que faltava em decorrência da falta de novidade". Assim é afirmado, ao mesmo tempo, que o discurso detém os meios de gozar na medida em que implica o sujeito, mas que o sujeito só poderia estar implicado pelo que excede o discurso nessa passagem, de um rasgo. $\mathrm{O}$ riso é o signo do sujeito, mas o sujeito sendo doravante não idêntico a si mesmo, não goza mais, tudo que pode fazer é tentar recuperar "um fragmento de possibilidade de gozo".

Ainda em "Mais além do princípio do prazer" (1974f), no capítulo sobre a repetição, vamos encontrar que originalmente, o sujeito, em relação ao que o conduz a algum declínio do gozo, nào poderia se manifestar senão como repetição, e repetição inconsciente. $O$ gozo é visado num esforço de reencontro, mas, pela virtude do signo, alguma outra coisa ocorre em seu lugar, uma marca, e nessa falha resvala o objeto sempre já perdido.

No mito de "Totem e Tabu", Freud (1974e) vai marcar a impossibilidade do gozo sexual reservando-o apenas ao pai da horda primitiva, que desfruta de todas as mulheres. Por isso, esse pai 
originário (Urvater) obriga todos os filhos a ligaçòes em que suas tendências sexuais sào inibidas quanto ao fim. Assim o mito ocorre no lugar onde, no sistema simbólico, no sistema do sujeito, o gozo sexual não é em lugar algum simbolizado nem simbolizável.

Ao correlacionar a curiosidade sexual e o desejo de saber, Freud deu um passo decisivo. Procurar desmascarar o que está envolvido no gozo na medida em que ele, estando excluído, conduz a freqüentar o Outro da linguagem como lugar onde algo se sabe. O saber é o preço da renúncia ao gozo, e é nesse sentido que poderíamos entender a castração. É também o ponto "fraco" que o discurso analítico permite descobrir, esse ponto mesmo de junção obscura do objeto a - a saber, aquele onde o sujeito pode reencontrar sua essência real como falta-a-gozar, algum representante que tenha tido de designar para si - com o campo do Outro na medida em que nele se ordena o saber, esse domínio interdito ao gozo. (Lacan, 1965).

A linguagem funcionaria como um diafragma do gozo, que ao mesmo tempo the serve como barreira e como passagem. $O$ inconsciente e suas formações são meios de possibilitar o gozo. O inconsciente é um trabalho onde a matéria prima é o gozo e o produto o discurso.

Lacan desenvolve o conceito de gozo pela via do direito, da filosofia do direito de Hegel. A teoria do direito se estabelece como regulação das restrições impostas ao gozo dos corpos, ou seja o contrato social. O que é licito fazer? Até onde podemos chegar com o próprio corpo e com o corpo dos outros? Referem-se portanto às barreiras ao gozo, do lícito e da licença.

Em 1966, tratando do tema "Psicanálise e Medicina", Lacan (1985a) relembra a experiência tantas vezes repetida por nós médicos, obrigados a constatar que sob a aparência de uma demanda de cura, esconde-se muitas vezes o desejo de apegar-se à doença, o que leva ao fracasso todo o progresso que a técnica oferece ao médico. O que movimenta o inconsciente do paciente ao amor do sintoma senão o gozo?

Ainda nesta conferência Lacan diz: "...O que eu chamo gozo, no sentido onde o corpo se experimenta é sempre da ordem da tensão, do forçamento, do gasto até mesmo da exploração. Sem dúvida há gozo ao nível onde começa a aparecer a dor e nós sabemos que é neste nível da dor que se pode provar toda uma dimensão da origem do ser, que de outra maneira restaria perdida".

"Gozar de uma boa saúde", do dizer popular, pode significar exatamente o contrário do gozo do corpo enquanto experiência vivida por ele mesmo. A medicina está assim dividida entre os alvos do prazer e do gozo, e em geral assume o papel de tecer barreiras ao gozo. Outras vezes, sem perceber, o médico e também o psicanalista, tornam-se o instrumento do gozo. Para mim, o hipocondríaco e o perverso poderiam ser exemplos interessantes.

Resumindo: o gozo é inconsciente, da ordem da tensão, vivido no corpo, o sujeito só tem notícia pelos seus efeitos no corpo. As formações do inconsciente sào uma elaboração e um deciframento sempre inacabados desta matéria prima, como um diafragma que permite que um certo gozo se vincule a estas formaçòes, denominado por Lacan de gozo fálico ou gozo fora do corpo ("hors corps"). O gozo do corpo é da ordem da pulsão de morte, tentativa de reencontro com a Coisa, fora do campo simbólico. Como exemplo poderíamos pensar no gozo do drogadicto, do alucinado, do suicida e porque não do canceroso, do hipertenso, do diabético? 
O princípio do prazer e o desejo (Wunsch) se opõem ao gozo. O prazer é vivido conscientemente, é da ordem do relaxamento, da queda da tensào, comparável ao disjuntor que desliga automaticamente quando a tensão elétrica está sobrecarregada. Um bom exemplo desta relação gozo/prazer é o orgasmo. Pode-se criar condiçòes ótimas de excitaçào numa relaçào sexual, a tensão é máxima de gozo até o momento do orgasmo que desarma a excitação, sendo seguido pela "morte" do pênis.

Qual a relação entre o gozo e a castração? Há entre eles uma oposição fundamental e que pode ser o eixo na direção do tratamento psicanalítico. $O$ sujeito deve renunciar ao gozo do corpo em troca de um outro gozo, próprio aos seres assujeitados à Lei. O gozo originário, gozo da Coisa, gozo anterior à Lei da Castraçào é um gozo interdito, mau-dito, que deverá ser recusado e substituído por uma promessa de um gozo fálico que resulta da aceitaçào da castração. "Tu não podes te proporcionar o que tu perdeste".

A incorporaçào do ser à linguagem é a causa de um exílio definitivo e irreversível em relaçào à Coisa. A Coisa, numa definiçào que the dá Lacan no seminário "A ética da psicanálise" (1986): "...é o que do real padece o significante". A palavra é o mar que ficou atrás do navio, o sulco que não pode alcançar a carruagem que a produziu. Só podemos reconhecer a carruagem e o navio pelos traços que eles deixaram em sua passagem. A terra, o mar, o corpo em uma palavra portam a inscrição do irrecuperável. A palavra marca-se na carne e faz aí um corpo simbolizado nas trocas com o Outro. Falar, pensar, passar pelos significantes da Lei: tais sào os efeitos da falta do objeto que colocam assim o lugar da Coisa (Ding).

Pois bem, que dizer então da psi- cossomática? Uma lesão de órgào poderia ser pensada como o gozo do órgão? Lacan propòe a lesão de órgào, por ele denominado fenômeno psicossomático como uma impossibilidade de articulaçào simbólica, dentro da cadeia significante que se interromperia diante de um real insuportável, um apelo significante, misto de som e imagem, năo necessariamente palavra, mas que levaria a uma espécie de emassamento ou fusào do par significante $S 1 / \mathrm{S} 2$ resultando numa inscriçào no real do corpo (Lacan, 1988 a, 1988b). Poderíamos pensar que a lesão de órgào ocorre quando o sujeito leva muito longe a barreira do gozo. Então o sujeito nào goza mais com as formações do inconsciente, com os significantes do sujeito submetido à lei da castração, mas goza com o eczema, com a úlcera, com o câncer e com a amputaçào.

A contingência deflagradora do fenômeno psicossomático poderia relacionar-se com situações atuais insuportáveis ou uma atualização de um núcleo patógeno inconsciente, como significantes datais ligados a perdas afetivas. Segundo Jean Guir (1992), pode-se ainda pensar a lesào de órgào como um pedido de reconhecimento, e a "escotha" inconsciente do órgão uma resposta ao desejo de um outro da família a quem a criança foi muito ligada ou seduzida.

Penso que a psicossomática é um gozo local, que obedece a uma condiçào fantasmática que exclui o significante. Portanto nào haveria uma estrutura psicopatológica psicossomática, ou um sujeito incapaz de articular simbolicamente seus traumas por um excesso de estresse ou ainda, incapaz de produzir formações inconscientes, como uma deficiência global estrutural, conforme propòe a Escola Psicossomática de Paris - P.Marty, M'Uzan e outros (Marty, 1993). 
() que observo na clínica é, ao contrário, pacientes que após a eclosào da doença, passam a um empobrecimento da vida psíquica, volvendo sua libido para a lesão, tornando-se um sujeito-lesào. Parece que o sujeito-lesâo se comporta, antes de tudo, como um "apaixonado". A paixào está muito mais para o lado do gozo que do prazer. O apaixonado é absorvido pelo objeto da paixào, num retorno narcísico que levao ao desgaste do corpo, podendo culminar na morte. Daí decorre uma dificuldacle técnica que talvez especifique um pouco o atendimento a pacientes psicossomáticos, ou seja possibilitar um corte com essa via de gozo e relançar o discurso do inconsciente.

No que se refere a esta "passagem do psíquico para o somático", vejo-a como um processo altamente dinâmico e bidirecional, cujo resultado final depende de uma questào de investimento, Freud talvez chamasse economica. Desta dinâmica resultará o prognóstico, no sentido da reversibiliclade, ou quando esta nào é mais possível, de um sofrimento menor.

A título de exemplo, gostaria de citar um paciente com câncer de próstata metastático, que acompanho há um ano, cujos sintomas iniciaram-se no período de doze meses após a morte do pai e de um neto a quem era especialmente ligado, tendo acompanhado as cirurgias por uma cardiopatia congênita até sua morte. Intensamente melancólico no início do tratamento, chorava muito e lamentava-se por nào ter morrido no lugar do neto quericlo. Fomos trabalhando sua história de vida, as etapas do tratamento, a mutilaçào da orquiectomia, as sessòes de quimioterapia, até que um dia trouxe um sonho, onde seu neto the aparece e "...conversam por um tempo muito longo, numa conversa de adultos". A elaboraçào deste sonho, a partir do qual pode liberar-se dos cuidados e das culpas em relaçào ao neto, teve um tal efeito de apaziguamento de sua tristeza, que o paciente passou a ganhar peso, dormir melhor, pensar no futuro e fazer planos, mesmo sabendo da gravidade de sua doença. As metástasés estão lá, nos ossos e na medula óssea, mas parece que desaceleraram. Pelas estatísticas sua esperança de vida seria de três a seis meses.

Num outro caso uma paciente de cor parda sofrendo um quadro depressivo grave e ideaçòes suicidas, percebe na análise sua impossibilidade identificatória. Sendo o lado materno da família da raça negra, e o lado paterno da raça branca, é enviada pela màe descle bem pequena para morar com a avó paterna, numa tentativa de aproximar as duas famílias que nào aceitavam o casamento dos pais. Tentativa malograda, a rejeiçào se estabeleceu em seu inconsciente como uma impossibilidade de existir. Após um sonho oncle se vê metade branca e metade negra, como o símbolo do Yin-Yang, mas que nào se misturavam, e que seu lugar na vicla era de embaixatriz dos pais, passou a melhorar. Mas logo em seguida faz espontaneamente uma hérnia de disco lombar. A associaçào de coluna (om eixo, com manter-se sobre o próprio corpo vem à tona. A neuro-cirurgia acabou acontecendo, mas a paciente se curou da depressão.

Este caso me parece um caminho inverso, o corpo participou do caminho de cura possivel para esta paciente. Num outro caso que acompanho, um quadro de Miastenia Gravis aparentemente transitório, surgiu num momento importante de ressubjetivação do paciente durante a análise.

Por último, começo a atender uma pessora apresentando uma doença de autoimunidade. No momento se configura uma esclerodermia, que se caracteriza por um endurecimento da pele, 
mas que teve seu início após uma tireoidectomia por doença de BasedowGraves, também autoimune. Há toda uma história de surras de couro de cabresto na infância, mas o que me interessa apontar é a contingência deflagradora.

A paciente estava grávida, no sexto mês (impressionante a incielênciá de patologias da tireóide na gravidez!). Morava em uma casa de parede-meia com um casal vizinho, acordando várias noites extremamente assustada, ouvindo os gritos e ameacas de morte das brigas deste casal. No prazo de um mês comeca a sentir-se muito nervosa, tremores nas màos, emagrecimento progressivo. O parto transcorre bem, mas o quadro clínico se agrava. Durante um ano percorrerá os médicos de sua ciclade, chegando a receber altas doses de calmantes, sem efeito. Até que um dia, a irma olha para ela e faz o diagnóstico: "será que você nào está com a mesma doencea da màte? ollie o seu pescoço!" Nesta mesma sessào a paciente faz a ponte. Nào eram as brigas dos vizinhos que the causavam estresse, mas no que a remetiam ao cenário da infância. Seus pais brigavam muito, e ouvia sua màe dizer que cortaria o pescoço de seu pai com o machado quando ele estivesse dormindo. A casa de sítio não tinha forro e a paciente oscilava entre o desespero das brigas dos pais e o prazer de ouvi-los nas relaçoes sexuais.

Afirmar que o psicossoma é uma unidade, comportá conseqüiências muito mais profundas do que o nosso pensamento estruturado e contaminado $\mathrm{pe}^{2}$ la concepcào dualista é capaz de conceber. (irodkeck, em 1923, no seu Livro d'Isso4, afirmava que em cada célula estava presente todo o ser bissexuado, cincuüenta anos antes das idéias do corpo humano como um corpo holográfico, onde a parte representa o todo, e antes de se conhecer o DNA.
O que leva cada sujeito humano à "opçà" do corpo como lugar de gozo, neste ou naquele órgao, mobilizando a organizaçà) arcaica de seu corpo primitivo ainda irrepresentável e de limites imprecisos, esconde-se em sua história e em algum "recanto" impossivel e temido de seu inconsciente. A psicossomática apresenta-se hoje como um importante campo de pesquisas e que integra os legados psicanalíticos herdados de Freud e seus continuadores. 


\section{REFERÊNCIAS BIBLIOGRÁFICAS}

BRAUNSTeIN, N. (1992). La fouissance, um concept lacanien. Paris, Point Hors Ligne.

FREUI), S. (1974a). Sobre la justificación de separar de la neurastenia un determinado Síndrome em cualidad de neurosis de angústia. In: Obras completas. Buenos Aires: Amarrortu., vol.3. [1895].

FREUI), S. (1974h) Fragmentos del análisis de um caso de histeria. In: Obras completas. Buenos Aires: Amarrortu., vol.7. [1905].

FREUD, S. (1974c) El chiste y su relación con lo inconciente. In: Obras completas. Buenos Aires: Amarrortu., vol. 8 [1905].

FREUI), S. (1974d) Perturbación psicógena de la vision según el psiccanálisis. In: Obras completas. Buenos Aires: Amarrortu., vol. 11 [1910].

FreUD), S. (1974 e) Tótem e Tabú. In: Obras Completas. Buenos Aires: Amarrortu , vol. 1 (1912-1913].

FREUD, S. (1974f). Más allá del princípio de placer . In: Obras completas. Buenos Aires: Amarrortu., vol.18, [1920].

GRODDFCK, G. (1984) O liero D'Isso . Sào Paulo: Perspectiva.

GUIR, J. (1992). A psicossomática na clinica lacaniana. Rio de Janeiro: JZF.

KAUPMANN, P. (1996) Carta 52 - correspondencia Freud-Fliess. In: Dicionário Enciclopédico de Psicanálise - O legado de Frende Lacan. Rio de Janeiro: JZE.

LACAN, J. (19)(8-1969) O Seminário, Livro 16. De um outro ao Outro. Seminário inédito.

LACAN, J. (1985) Psicanalisis e medicina. In: Intervenciones y Textos 1. Buenos Aires: Manantial.

LACAN, J (1986). O Seminário, Liuro 7. A ética da psicanálise . Rio de Janeiro: JZE [1959-1960].

LACAN, J. (1988 a). O Seminário, Libro 2. O en na teoria de Frende na técnica da psicanálise. Rio de Janeiro: JZE. [1954-1955]

LACAN, J. (1988h)) O Seminário, Livro 11. Os quatro conceitos fundamentais da psicanálise. Rio de Janeiro: JZE.. [1964]

MARTY, P. (1993). A psicossomática do adulto. Porto Alegre: Artes Médicas. 